\title{
Lugares de encuentro en los espacios del horror. Acercamiento testimonial a los centros de detención y/o tortura chilenos $^{1}$
}

Meeting places in space of horror. Testimonial approach to the Chilean Detention and /or Torture Centers

\section{José SANTOS HERCEG}

IDEA/ Universidad Santiago de Chile · jose.santos@usach.cl

Doctor en Filosofía por la Universidad de Konstanz, Alemania. Es investigador del Instituto de Estudios Avanzados (IDEA) de la Universidad de Santiago donde además imparte los cursos de Filosofía latinoamericana, Epistemología y el Seminario de Especialidad Pensamiento y Cultura. Entre sus publicaciones se encuentran Pensamiento filosófico en América Latina, liberación, interculturalidad e historia de las ideas; Interculturalidad e Integración. Desafios pendientes para América Latina y Conflicto de Representaciones. América Latina como lugar para la filosofía.

Resumen: El presente escrito busca acercarse al tema de la resistencia al interior de los Centros de Detención y/o Tortura chilenos desde la perspectiva de los lugares. Se sostiene que los prisioneros constituyen espacios con los que se vinculan positivamente y que les permiten mantener su humanidad en medio del horror. A modo de ejemplos, se estudian los espacios de comunicación, los sitios para el amor y los lugares sagrados.

Palabras Clave: Prisión, Resistencia, Encuentro, Comunicación, Amor, Sagrado.
Abstract: This paper seeks to approach to the topic of the resistance inside the Chilean Detention and / or Torture Centers from the perspective of the places. It is argued that prisoners construct spaces which are linked positively and allow them to maintain their humanity in the middle of horror. As examples, we study the spaces of communication, the places for love, and the sacred places inside this Centers.

Key Words: Prison, Resistance, Meeting, Communication, Love, Sacred.

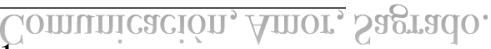

1 Este trabajo forma parte de la investigación titulada "Campos prisioneros en Chile. Reconfiguración de los lugares y las subjetividades" (FONDECYT No 1140200).
} 
En cada una de las dictaduras militares del Cono Sur se dieron la prisión política, la tortura y la desaparición ${ }^{2}$. Pese a la existencia de una matriz común, no en todos los países aparecen de igual forma ni con la misma intensidad (Pereyra, 2004). El caso de Chile se caracterizó muy especialmente por la privación de libertad masiva y la tortura sistemática y generalizada. Para ello se contó con 1.168 Centros de Detención y/o Tortura ${ }^{3}$ conocidos y reconocidos oficialmente hasta hoy. Acerca de los lugares de prisión y tortura en general, hay una vasta bibliografía. Sobre los lugares de prisión chilenos, sin embargo, es poco lo que se ha escrito. Solo es posible encontrar trabajos puntuales acerca de algunos lugares emblemáticos: Villa Grimaldi (Geis y Jiles, 1984; Fuenzalida, 2009), Londres 38 (Landaeta, 2007; Escobar, 2011; Lazzara, 2011; D’Orival y Viera, 2011), el Estadio Víctor Jara (Fuentes, Sepúlveda y San Francisco, 2009 y 2010), Tres Álamos (Camus, 1989) y el Estadio Nacional (Durán 2011, Bonnefoy, 2005). Sobre los restantes 1.162 lugares, prácticamente no hay investigaciones.

Por otra parte, no es mucha la literatura que aborde el problema de la prisión política desde la perspectiva espacial ${ }^{4}$. En el presente trabajo intentaré hacerlo a través de los testimonios. Utilizaré principalmente aquellos que fueron escritos por las mismas víctimas y que luego fueron publicados en formato de libros. Tendré a la vista un corpus importante de obras aparecidas entre 1974 y 2014. Mediante el trabajo con estas fuentes buscaré ir dando forma a la representación que construyen las víctimas mismas de los lugares en los que fueron detenidos y torturados. No me interesa rastrear su adecuación a una posible verdad acerca de los Centros de Detención y/o Tortura, sino la compleja forma en que estos lugares se constituyen en los relatos que los contienen, amplificando sus sentidos. Como ha señalado acertadamente Amar “...los textos ponen en escena una versión con su lógica interna, no son una 'repetición' de lo real sino que constituyen una nueva realidad regida por leyes propias" (1990: 447). El testimonio, lejos de ser un "reflejo" de la realidad, configura una interpretación, crea una representación de la experiencia y de la verdad de las representaciones de las que no es posible hablar (Beverley, 1993:492).

\footnotetext{
${ }^{2}$ La base de este texto es una ponencia presentada en el congreso Donde habita el olvido. Herencia y transmisión del testimonio en América Latina. I. Congreso Internacional de Literatura y Derechos Humanos, Gargnano, Italia, 29 de junio a 4 de julio de 2015.

${ }^{3}$ En lo relativo a la denominación de estos lugares se ha escogido el de "Centro de Detención y/o Tortura" como un nombre genérico con el objeto de establecer que existieron en Chile diferentes tipos de centros. Hubo algunos destinados solo a detener y contener a los prisioneros sin que se torturara en ellos; hubo otros especialmente habilitados para torturar, a los que eran llevados los prisioneros para interrogarlos y luego eran devueltos a su lugar de detención, y hubo otros en los que se daban ambas prácticas, tanto la detención como la tortura, aunque en estos casos lo habitual era más bien que se detuviera tan solo un tiempo breve mientras se interrogaba.

${ }^{4}$ Excepciones son, por ejemplo, los trabajos de Silva y Rojas (2004, 2005 y 2011), el de Landaeta (2007), el de Pulgar (2011) y el de Moret (2010).
} 
Como categoría central para este análisis utilizaré la de "topofilia”. Es Gaston Bachelard quien utiliza por primera vez el término "topofilia” para referirse al "valor humano de los espacios de posesión, de los espacios defendidos contra fuerzas adversas, de los espacios amados” (2000 [1957]: 22). Bachelard concibe el lugar como un "espacio vivido" 5 . Esencial para este autor es que la carga afectiva sea positiva. En este mismo sentido es que Tuan habla de "topofilia", como "las manifestaciones específicas del amor humano por el lugar.” (2007: 129). Yory, por inspiración confesadamente heideggeriana, lleva el concepto de "topofilia”, más allá y habla de una dimensión "espaciante” del ser humano. Esto se refiere a que el ser humano “...se define a sí mismo como un ser espaciante: el que "espacía", el que habitando "abre" el espacio..." (1998: 9), en el sentido en que "carga de sentido y significación” (1998: 3). El autor habla de una especial forma de "philiación" (1998: 8). Una filiación que ya no es tan solo de orden psicológico - afectiva-, sino que sería también y sobre todo ontológica (Cf.: 8). Somos "seres espaciantes", dirá el autor en tanto que establecemos con el mundo “...una particular clase de philiación... gracias a la cual, a la vez que el primero se "mundaniza” el segundo se "humaniza"”. (1998:13). El ser humano en tanto que "espaciante", es decir, poseedor de una naturaleza "topofílica”, sería constructor-apropiante de los lugares en tanto que los humaniza.

Me interesa ver de qué forma se activa esta construcción-apropiación entre quienes estuvieron detenidos y fueron torturados. No todos los lugares son el objeto de la observación actual, sino tan solo la construcción-apropiación de lugares de resistencia. El trabajo de Pilar Calveiro (2001), en relación con la resistencia en los campos es, sin duda, fundacional en este sentido. Ella sostiene que los Campos de Concentración mismos generan constantemente "líneas de fuga y los dispositivos que disparan contra el núcleo duro del poder y contra sus segmentos, abriendo brechas" (2001: 112). Su intuición apunta a que hay muchas formas de "fugarse" de los Campos, entre las cuales la "física" es tan solo una más. Lo importante es tener en cuenta que todas tienen en común el que están “....asociadas con la preservación de la dignidad, la ruptura de la disciplina y la transgresión de la normatividad...” (114). Se trata, como dice la autora, de cualquier estrategia para "sobrevivir sin entregarse, sin dejarse arrasar" (114). En general, Calveiro concluye que los objetivos de todas las resistencias tienen que ver con mantener o recuperar la humanidad, con adquirir algún grado de control sobre la situación o algún nivel -por mínimo que sea- de libertad, con restablecer o generar lazos de solidaridad y cooperación entre los prisioneros (127).

Interesa situarse justamente en el marco de estas estrategias de resistencia, proponiendo la construcción-apropiación de lugares - propia del ser humano- como una de ellas; tal vez una

\footnotetext{
5 “El espacio captado por la imaginación no puede seguir siendo el espacio indiferente entregado a la medida y a la reflexión del geómetra. Es vivido. Y es vivido, no en su positividad, sino con todas las parcialidades de la imaginación” (Bachelard, 2000 [1957]: 20).
} 
José Santos Herceg. Lugares de encuentro...

fundamental por tratarse de la activación de una estructura ontológica. Es posible fugarse en la medida en que el sujeto construye y se apropia del lugar, volviéndolo algo diferente del llamado "campo del poder"; construyéndolo, apropiándoselo como algo distinto: un lugar de resistencia. Es poco lo que aparece en los testimonios sobre estos lugares de resistencia. En general, las alusiones a ellos son marginales, primando, por mucho, la referencia a los lugares como espacios del poder, del dolor, del horror.

En el caso de los "lugares de resistencia”, estamos en presencia de aquello que Jorge Montealegre llama con razón "memorias eclipsadas" (2013). Recuerdos callados, ocultos; aquellos de los que poco se habla, a los que se refiere solo ocasionalmente y casi sin quererlo: "...acciones y actitudes que, generalmente, no se declaran ni son objeto de preguntas" (2013: 24), porque son "experiencias positivas que permitieron sobrellevar la adversidad con humor, creatividad y espíritu comunitario" (2013: 24). Experiencias, acciones positivas en medio del más terrible de los trances, momentos de alegría, incluso de risa. Espacios para el juego y la diversión, para la creatividad, donde es posible sentirse protegido y amparado. Como buscaré mostrar ahora, en un contexto de dolor extremo existieron lugares de encuentros profundamente humanos.

\section{Los baños: espacio de comunicación}

En los contextos de reclusión, especialmente en los casos en que los sujetos están en régimen de incomunicados, la posibilidad de diálogo está limitada a su menor expresión. A juzgar por los testimonios, sin embargo, la necesidad de intercambio con el otro busca sus modos para manifestarse y se van constituyendo diferentes lugares para el diálogo. Entre ellos, el que más destaca es el caso de los baños, de las letrinas. Se trata, en principio de lugares muy poco aptos para el encuentro.

Las letrinas son habitualmente de una construcción precaria y aparecen descritas casi siempre como extremadamente sucias, hediondas, incómodas. Valdés habla insistentemente de "tablas chorreadas de excrementos", de "tener que taparse la nariz para entrar" (1978: 89), las describe como “...dos troncos también chorreados de mierda" (1978: 100), “tablas compenetradas de orines y mierda” (121). Luz Arce comenta que los baños en Tejas Verdes “...eran unos cajones -cajas negrasmuy sucios, malolientes y llenos de gusanos” (1993: 62). Los baños en lugares como el Estadio Nacional, por ejemplo, siempre están, según los testimonios, inundados y chorreantes. Montealegre habla de "El piso frío y los baños inmundos y mojados..." (2003: 56). Los del Estadio Chile no son diferentes. Relata Carrasco que "Los retretes rebalsaban excrementos y los orines corrían por los pasillos y bajaban entre las butacas donde dormíamos" (1991: 62).

Los baños, pese a ello, se vuelven lugares de encuentro. Esto, fundamentalmente por dos razones. Por un lado, porque simplemente no hay intimidad ni privacidad alguna en ellos. Una experiencia 
extrema en este sentido es la de los "chutes" en los barcos: enormes tarros instalados en medio de las bodegas para que los prisioneros orinaran y defecaran. Escribe Joui al respecto: "El acto de hacer sus necesidades siempre ha sido privado, individual, unipersonal. Pero en estas condiciones, uno se bajaba los pantalones, se sentaba en esa tabla puesta en el borde del tacho y delante de la mayoría de sus compañeros, empezaba a obrar...” (1994: 40). Valdés relata una experiencia cercana. "Quedamos culo contra culo, difícilmente de frente. Yo quedo con el culo de Rubén, muy pálido, lampiño, enfrente mío, casi tocándome las rodillas” (1978:100). En los baños, los prisioneros se topan en el sentido más elemental posible: están forzados a compartir. Por supuesto, allí no hay lugar alguno para el pudor.

Por otro lado, en los baños hay mayor libertad. En tanto que se afloja la vigilancia mientras los detenidos hacen sus necesidades, se genera un espacio para el intercambio y el encuentro. Quijada se refiere a la distinción entre "la corta” y la larga" (1990: 22-23), aclarando que la “...'larga' tenía sus ventajas: en ella se podía conversar, intercambiar unas cuantas palabras, enviar un mensaje o hacer una advertencia, en rápidos diálogos” (24). En el Documental de Ancelovici, Chacabuco, voces del silencio, comentan dos exprisioneros que las letrinas estaban en el centro y que era un lugar de reunión, de conversación. Benavente describe nítidamente lo que se viene diciendo.

La situación era un tanto pintoresca. Los del frente veían a su oponente y viceversa. Los del lado, a veces, cuando la necesidad era generalizada, estaban codo a codo. En un comienzo nadie se sentía tranquilo, aunque el lugar era ventilado y con agua corriente todo el día. Algunos, para no desperdiciar el tiempo, leían o conversaban. Era un lugar de encuentro muy especial y democrático. No era extraño encontrar frente a un campesino de Colchagua, que vaciaba sus intestinos, al doctor Bartulín que hacía lo mismo, mientras la conversación fluía” (2003: 18).

No solo son lugar de encuentro, sino que también de igualación socioeconómica y cultural. Al momento de "vaciar los intestinos" todos son iguales y en esa igualdad se puede dialogar. Un extremo en este sentido podría constituirlo el proyecto de letrinas ideado por Carlos Matus y realizado por Miguel Lawner en Dawson: “...Matus propone las dos letrinas en forma de S, a la manera de un sillón 'toi et moi. Así, mediante un leve giro de la cabeza, será posible -mientras cagamos- mantener un amable coloquio entre ambos ocupantes de las letrinas" (Lawner, 2004: 39-40).

Lugar privilegiado de encuentro, el baño y la letrina constituyen un espacio central, medular de los Centros de Detención. El cuento titulado Un parto en el desierto de Hugo Valenzuela comienza con una descripción del galpón en el que estaban los baños. Las letrinas estaban distribuidas de tal forma que “... cuando uno ejercía el sagrado derecho, quedábamos frente a frente y los pudores se iban a la misma. Esto era como una peluquería de barrio, quedábamos al día del comidillo, del rumor del desierto" (Facebook, 9 de febrero de 2015). 
Incluso en los lugares de mayor dureza y rigor, los baños siguen siendo un espacio de encuentro. Cuenta Nubia Becker que "En la Torre, las celdas eran más chicas; como perreras, y la incomunicación era más rigurosa. De los que se llevaban allí, sólo sabíamos por casualidad, cuando por descuido de algún guardia, nos topábamos en el baño...” (Rojas, 1987: 59).

En estos espacios extremadamente rudos y controlados, se produce un desplazamiento: los baños pasan a ser lugares de comunicación, se vuelven espacios para el traspaso clandestino de información. Hernán Valdés cuenta que “A través de los WC una mujer ha pasado un mensaje” (1978: 197). En Cuatro Álamos, Nubia Becker usaba los baños para comunicarse con su compañero: "Nos dejábamos papelitos en el baño" (Rojas, 1987: 79). Haraldo Quinteros cuenta que "a través de toda una acción concertada por medio de mensajes en el excusado (...), pudimos estar de acuerdo en lo que diríamos en los interrogatorios" (1979: 66).

\section{Sitios para el amor cautivo}

El término "amor cautivo" lo usa Montealegre en su testimonio (2003:107) y puede aplicarse, me parece, a varios casos y a varios lugares. Al que alude expresamente Montealegre, por cierto: el encuentro en la piscina del Estadio Nacional. Montealegre relata en un capítulos titulado "Frazadas para la Piscina” (2003:105 y ss), de qué manera Luis Alberto Corvalán y Ruth Vuscovic, su esposa, pudieron encontrarse estando prisioneros. Ambos estaban detenidos en el Estadio Nacional: ella estaba en la piscina, él en los camarines de la cancha de fútbol. En algún momento que se requirieron voluntarios para llevar frazadas y colchonetas a la piscina, “...como en un pacto silencioso, no tuvimos ni un asomo de dudas para que la oportunidad fuera aprovechada por Luis Alberto. Y se le facilitó el camino para que resultara casualmente voluntario" (2003:106).

Montealegre refiere y cita directamente el testimonio del mismo Corvalán quien relata ese momento de encuentro con su pareja en la piscina en un capítulo que titula "Un beso clandestino" (2007 [1974]: 43 y ss). Allí cuenta su llegada al sector de la piscina: "Alguien me toma de la mano y me aparta del grupo. Entonces veo a Ruth. Viene con su característica flor en el pelo y su sonrisa de marfil. Comprendo que está entera, de pie y combatiendo. ¡Qué importan los centinelas y sus fusiles! ¡Abro mis brazos para coger su aroma y darle mi fuerza!” (44). Las demás prisioneras toman las cosas y se van, ellos se dirigen a los camarines. "Aprieto la cintura de mi compañera y acaricio su pelo. Nos han dejado solos en un entendimiento tácito. Miro sus ojos profundos que me cuentan de su tierno amor, veo en ellos la respuesta militante de las mujeres del pueblo ante la represión. Pienso que no lograrán doblegarlas. Cojo su rostro entre mis manos y la beso, con un beso prisionero y clandestino" (44).

Cercano es lo ocurrido en la Iglesia de Chacabuco. Joui relata el encuentro con su mujer cuando lo visita en la prisión: 
José Santos Herceg. Lugares de encuentro...

Después de grandes abrazos y besos con mi señora, pasamos al lugar que nos habían destinado. Una banca puesta en una especie de palco del Teatro. Empezamos a conversar, a reírnos, a llorar por todos estos meses sin vernos.... En la tarde conseguimos permiso para ir a la Plaza o a la Iglesia. Era como un paseo (...) había un soldado con su metralleta cuidando la entrada de la Iglesia. Le solicitamos permiso y entramos. La nave estaba desocupada, sin bancas, sin altares y sin efigies. Éramos tres parejas (...) En cada esquina de la Iglesia, había unas pequeñas piezas, en la que cada pareja entró, y faltándole el respeto a Dios, sin querer queriendo, hicimos el amor a nuestras esposas. Más de seis meses sin amor, figúrense como fue este encuentro sexual amoroso. Divino, amorosamente divino" (2003:137).

La escena del encuentro con los seres amados se repite con los otros prisioneros de Chacabuco que tienen visita. Así lo señala Benavente: "Allí llegaron las esposas, novias, hijos o padres, ansiosos de comprobar que sus bienamados estaban vivos. Cada segundo de esta felicidad vigilada y restringida debía ser estrujado al máximo” (2003:64). Encuentro y alegría "tras las electrificadas cercas”, dice Benavente (2003:64). En los espacios permitidos, algunos, relata, “...compartían por algunas horas, momentos de tierna proximidad". Hablando luego de su esposa y sus penurias, Benavente comenta que "En precarias condiciones de salud, se encontraba allí, junto a Renecito, en ese pequeño espacio florido del desierto. Cual paloma herida se refugiaba en el pecho del amado" (65). El remate del pasaje del testimonio de Benavente alude a que "En cada grupo se repitió, en formas diversas, la grandeza del amor humano" (2003:65).

Los encuentros amorosos no siempre fueron en cuerpo presente. Casassus cuenta de la llegada a su celda de un músico, "uno de verdad” como dice, que tocaba música clásica. Al atardecer de cada día “...se instalaba en la ventana y le silbaba a su mujer, también del MIR y también música. Ella le respondía, y así iniciaban un diálogo musical. Cada uno desde su celda, nos daban a escuchar las serenatas más hermosas, tanto que nunca fueron interrumpidas por las fuerzas del orden" (2013:91).

Los encuentros entre seres queridos no tienen lugar solo entre parejas, sino también entre padres e hijos. Jorge Montealegre cuenta la siguiente anécdota:

Cierta noche, a la hora en que casi todos ya dormían, se abrió la puerta del camarín. La luz que se colaba desde el pasillo rompió la oscuridad y proyectó la silueta de un soldado que se acercaba silencioso a un compañero. Le tocó su cabeza, le hizo un cariño y le entregó un sándwich. Le besó las mejillas, se levantó, avanzó sigilosamente y cerró la puerta tras de sí ... Su puesto estaba afuera, al lado de la ametralladora que custodiaba el pasillo. Adentro, en penumbras, el obrero con ojos brillantes se acomodaba para comerse el valioso regalo. Era el pan que le había dado su hijo que, ese día, en el Estadio, cumplía con el Servicio Militar Obligatorio” (122-123).

Los hermanos también protagonizan encuentros en los Centros de Detención, encuentros siempre dolorosos como el de Luz Arce con su hermano en Villa Grimaldi (1993: 112 y ss). Luego de las 
José Santos Herceg. Lugares de encuentro...

torturas y de una oferta concreta de colaboración, los dejan una noche para meditar. "¡Guardia!, póngales la venda. Sin amarras, déjalos en un rincón, juntos, pueden hablar entre ellos” (1993:114). El rincón como lugar de encuentro entre hermanos. Como las casas de Chacabuco que sirvieron también para acoger a hermanos. Así relata Corvalán la llegada del hermano de un prisionero a Chacabuco. "Si es Ernesto! ¡Más flaco quizás, pero es él!’ ¡Juan... Juan! ¡Mira quién viene con los nuevos! ¡Es tu hermano!' Ernesto encabeza ahora el batallón de los nuevos. Nos ha visto y levanta la mano para saludarnos. Abren el portón del campo" (2007: 74). Inmediatamente el nuevo es adoptado en la casa del hermano. "A Juan se le ocurre una idea, que aunque arriesgada es aceptada por todos nosotros. Que llevemos esta misma noche a Ernesto a nuestro pabellón, más directamente, a su casa. Le proponemos la idea a Ernesto y éste acepta de inmediato. Tomamos los bultos y partimos rumbo al sitio convenido: allí podremos seguir la conversa en un ambiente más reducido y también más seguro" (2007: 76). Hermanos en prisión que se encuentran en celdas, en cabañas, en casas: ambos sufrientes, ambos privados de libertad. Pero también hermanos en bandos opuestos que se encuentran, que se enfrentan. Como en la historia de los hermanos en el Estadio Nacional que se relata en el documental "Estadio Nacional" de Carmen Luz Parot (2011). Uno guardia, el otro prisionero.

\section{Altares y santuarios: lugares sagrados}

"Encuentros con lo trascendente" podría titularse este apartado: encuentros con aquello que está más allá de lo físico, de lo terrenal. Los Centros de Detención y/o Tortura son, en su sentido más evidente, espacios de una terrenalidad inigualable, en los que lo concreto, lo mundano, lo corporal adquiere un protagonismo absoluto. Los relatos testimoniales se resuelven en su mayor parte en alusiones a los asuntos más pedestres y cotidianos: descripción de comidas, dar cuenta de la habitación o de los problemas de la digestión, trastornos de sueño, conflictos de convivencia cotidiana, anécdotas, descripción pormenorizada de malos tratos y torturas, etc. En algunas ocasiones, estas descripciones se ven interrumpidas por relatos de otro tipo, relatos en los que lo físico es inundado por lo espiritual, transformado los lugares. Escribe Montealegre que "Cristo también estuvo en el Estadio Nacional. Más allá de la retórica, muchos llegan a sentir esa presencia” (2003: 93). El cristianismo era para los creyentes una luz, una esperanza, un sentido: "En medio del absurdo que vivíamos en el Estadio, nuestro cristianismo le daba ‘sentido' a la prisión y al sufrimiento. Cristo nos acompañaba...” (93). Repite Montealegre en varias oportunidades que “El Espíritu de Cristo estaba en el Estadio” (94).

Uno de los ejemplos en que mejor se evidencia esto es en la descripción que hace este mismo autor de su Primera Comunión: “Uno de esos domingos, me quedé en el camarín. Feliz intuición porque ahí, en el camarín siete, como en una catacumba, un cura prisionero celebró una misa que nunca 
olvidaré" (Montealegre, 2003: 97). En medio de la situación más extrema y la precariedad más absoluta se logró, en palabras del testimoniante "una hermosura profunda" (97). Tienden una frazada en el suelo, frazada que es "el manto de los pobres cristos del velódromo", ella sirve de mantel para un altar que no era más que el piso de baldosa. La prédica fue simple y directa: "Dios estaba con nosotros y si moríamos nos encontraríamos con Él en la eternidad. Con Cristo, su Hijo, nos encontraríamos ahí mismo en el camarín 7...” (97). Cuenta Montealegre que muchos años después se encontró con el cura que había celebrado ese día y le preguntó si su primera comunión había sido "legal”. El cura responde que sin duda lo fue. El camarín 7 del Estadio Nacional fue, en ese momento, un santuario, la frazada, un altar, el pan, el cuerpo de Cristo.

Las misas, de hecho, aparecen en los relatos de muchos de los prisioneros: misas en cautiverio. Algunas de ellas son recordadas con especial detalle e intensidad, en tanto que se experimenta un verdadero encuentro con Dios. Mario Benavente relata una impactante misa que ofició Mariano Puga en Chacabuco. Un momento tan sentido que, dice Benavente, "La misa había terminado. Un profundo respeto invadió el recinto. El padre Mariano Puga se retiró conmovido. Su figura quedó impresa en la retina de cada prisionero. Se podría ser católico, creyente o no creyente, pero su mensaje había sido de hondo contenido solidario" (2003: 145). Lawner se detiene en un momento parecido que tiene lugar en Dawson: "Noviembre se inició con un emotivo servicio religioso, efectuado por el padre Cancino en nuestro patio, con motivo del día de los difuntos, y al cual concurrimos casi todos nosotros" (2004: 46). Un oficio religioso muy especial fue el Bautizo de la hija de Juan del Valle en la capilla de la Penitenciaría de Santiago: "Cómo poder olvidar esos momentos Se llenó la capilla con compañeros prisioneros políticos y mientras tres de ellos cantaban 'Gracias a la Vida', de Violeta Parra, acompañados con sus guitarras, fue bautizada Marcela Odette...” (Del Valle,1997: 123). La misa más recordada, sin embargo, parecer ser la Misa Criolla de Ángel Parra en Chacabuco, que según cuenta el mismo autor, tuvo su origen en el intento del cantautor por demostrarle al Comandante del campamento que todos los prisioneros eran verdaderos "cristos".

Las misas, sin embargo, no son las únicas instancias en que los lugares de prisión y tortura se vuelven espacios en que se dan encuentros con lo trascendente. Estando prisionera y herida en el Hospital Militar, Luz Arce relata que la visita un sacerdote. Comienza entonces a recibir regularmente la Eucaristía en su habitación-prisión. Cuenta que "En la pared frente a mi cama había una cruz, y muchas veces en silencio, le dije: - “ ¿también sufriste, verdad? Y se iniciaron interminables diálogos con Él... Me sentía acompañada" (1993: 76). Una sala de hospital se vuelve lugar de oración.

Cualquier lugar puede transformarse en un santuario. Incluso una piscina que era usada como prisión se vuelve un espacio de oración y encuentro con lo trascendente, como en el caso de los Evangélicos en la Isla Quiriquina. Cuenta Witker que: 
José Santos Herceg. Lugares de encuentro...

El grupo tenía un líder, Julio Martínez (...). A las pocas semanas, en el gimnasio, Martínez había creado un grupo de evangelistas con quienes se dedicó a leer y comentar la Biblia. Luego vinieron las oraciones y los cánticos. Primero, a media voz; más tarde, un grupo se instalaba en una esquina, a las cinco de la tarde, para cumplir con Dios y su conciencia. El grupo evangélico crecía día a día. Martínez, Biblia en mano, daba consuelo y esperanza (Witker, 1974: 50-51).

Lo trascendente se manifiesta en los Centros también a través de los milagros. Estos espacios adquieren, en algunas oportunidades, un carácter de sagrado. En el Estadio Nacional, por ejemplo, se registran cuestiones milagrosas. Alberto Cozzi relata de qué manera un sándwich de queso se dividió entre 106 presos y no solo alcanzó para todos, sino que, incluso quedaron satisfechos: "Era verdad. En cierto modo nos sentíamos más satisfechos que si hubiéramos comido cada uno una parrillada" (2000:104). Cozzi hace la relación directa con el pasaje bíblico de la multiplicación de los panes. También Alberto Corvalán alude a un evento parecido en el Estadio, cuando relata la manera en que 5 naranjas, cuatro panes y un pedazo de queso sirvieron para alimentar a 156 prisioneros (2007[1974]:47-48). Jorge Montealegre vuelve sobre estas anécdotas en un capítulo que titula significativamente "La multiplicación de las migas” (Montealegre, 2003:108ss).

\section{Lugares de encuentro: conclusión}

Como se ha podido ver, en un contexto de dolor extremo existieron lugares de encuentros profundamente humanos. Pocos, sin duda, eclipsados, como dice Montealegre, pero existieron. Pasado el momento de la lucha contra la dictadura, de la denuncia y reivindicación, pasadas varias décadas desde la experiencia, en los testimonios más actuales aparecen cada vez con más frecuencia, referencias a estos lugares humanizados con los que se establecen vinculaciones afectivas positivas, a los que se retorna con emoción, con amor, con alegría. Lugares atesorados que han hecho posible la resistencia en medio del horror. 
José Santos Herceg. Lugares de encuentro...

\section{Bibliografía}

Amar Sánchez, Ana María. “La ficción del testimonio”. Revista Iberoamericana 151 (1990): 447-62.

Arce, Luz (1993). El Infierno. Santiago de Chile: Ed. Océano [Planeta].

Bachelard, Gaston (1957).La poétique de lespace. Paris: Presses Universitaires de France. Citado según la traducción de 2000.

Benavente Paulsen, Mario (2003). Contar para saber: Chacabuco, Puchuncaví, Tres Alamos (1973-1975). Santiago: Jy C producciones gráficas.

Beverley, John. "El testimonio en la encrucijada”. Revista Iberoamericana.164-165, (1993): 485-495.

Bonnefoy, Pascale (2005). Terrorismo de estadio. Prisioneros de guerra en un campo de deportes. Santiago de Chile: Ediciones Chile América-CESOC.

Becker, Nubia (Carmen Rojas), (1987), Recuerdos de una Mirista. Santiago de Chile: Ediciones del Taller. (Publicado nuevamente bajo el nombre Una mujer en villa Grimaldi, Pehuén Editores: Santiago de Chile, 2011).

Calveiro, Pilar (2001). Poder y desaparición. Los campos de concentración en Argentina. Buenos Aires: Colihue,

Camus, M. E. "Puchuncaví, Ritoque, Tres Álamos. La otra cara de los campos de concentración”. Análisis XII- 289 (1989): 33-37.

Carrasco, Rolando (1991). Prigué. Santiago de Chile: Ediciones Aquí y Ahora. (Edición original Moscú, Novosti, 1977)

Corvalán, Luis Alberto. (2007), Viví para contarlo. Santiago de Chile: Ediciones Tierra Mía, 2007. (Publicada originalmente bajo el título de Escribo sobre el dolor y esperanza de mis hermanos. Praga: Sofia Press, 1976).

Casassus, Juan (2013). Camino en la oscuridad. Santiago de Chile: Editorial Debate.

Cozzi Figueroa, Adolfo (2000). Estadio Nacional. Santiago de Chile: Sudamericana.

Del Valle, Juan (1977). Campos de concentración, Chile 1973-1976. Santiago de Chile: Mosquito ediciones.

D’Orival, Roberto y Stein, Viera (2011). “Londres 38”. Ciudad y Memorias. Desarrollo de Sitios de Conciencia en el Chile actual, Corporación Parque por la paz Villa Grimaldi: 193-199. 
Durán, Carlos (2011). “Estadio Nacional, Memoria Nacional”. Ciudad y Memorias. Desarrollo de Sitios de Conciencia en el Chile actual, Corporación Parque por la paz Villa Grimaldi: 148-156.

Escobar, América (2011). Memoria y materialidad Londres 38. Un estudio de caso. Tesis para optar al título profesional de antropólogo, Universidad de Concepción.

Fuentes, Manuel; Sepúlveda, Jairo y San Francisco, Alexander. "Hacia una arqueología del estadio Víctor Jara: campo de detención y tortura masiva de la dictadura en chile (1973-1974)" . Revista de Arqueología Histórica Argentina y Latinoamericana 4 (2010): 91-116.

Fuentes, Manuel; Sepúlveda, Jairo y San Francisco, Alexander. "Espacios de represión, lugar de memoria. El estadio Víctor Jara como centro de detención y tortura masiva de la dictadura en Chile”, Revista Atlántica-Mediterránea de Prehistoria y Arqueología Social 11 (2009): 137-169.

Fuenzalida, Nicole (2009) Villa Grimaldi, análisis de la configuración del espacio y arquitectura, en relación a las estrategias de represión y control de los cuerpos de detenidos y torturados. Hacia una Arqueología de la Represión Política en Chile. Informe de Práctica Profesional, Antropología, Universidad de Chile.

Geis, I. y Jiles. P. “Campo de Concentración. Tortura y muerte en la Villa Grimaldi”. Análisis VII- 86 (1984): 30-34.

Joui Joui, Sadi Renato (1994 y 2003): Chacabuco y otros lugares de detención. Santiago-Valparaíso, autoedición.

Landaeta, Romané. (2007). Historia y Memoria: Reconstrucciones de la represión en Chile: 1973-1974: Elcaso de Londres 38. Memoria de Máster. Universidad Autónoma de Madrid.

Lawner, Miguel (2004). Retorno a Dawson. Santiago de Chile, LOM.

Lazzara, Michael. “Dos propuestas de conmemoración pública: El Museo de la Memoria y los Derechos Humanos y Londres 38 (Santiago de Chile)”. Revista A contracorriente (2011) Universidad de California.

Montealegre, Jorge (2003). Frazadas del Estadio Nacional. Santiago de Chile: LOM.

Montealegre, Jorge (2013). Memorias eclipsadas. Duelo y resiliencia comunitaria en la prisión política Santiago de Chile: Asterión /USACH.

Moret, Zulema. "La Violencia del Lugar". Aisthesis : revista chilena de investigaciones estética, 48 (2010): 218-228. 
Pereyra, Daniel. “Argentina: militares torturadores”. Mientras Tanto 90 (2004): 79-96.

Peris Blanes, Jaume (2005). La imposible voz. Memoria y representación de los campos de concentración en Chile: la posición del testigo. Santiago de Chile: Editorial Cuarto Propio.

Pulgar, Claudio (2011). "Lugares de Memoria y Olvido, el derecho humano a la ciudad". Ciudad y Memorias. Desarrollo de Sitios de Conciencia en el Chile actual. Corporación Parque por la paz Villa Grimaldi: 110-118.

Pulgar, Claudio y Imilan, Walter (2011). "Un enfoque territorial para el estudio de espacios de memoria”. Ciudad y Memorias. Desarrollo de Sitios de Conciencia en el Chile actual. Corporación Parque por la paz Villa Grimaldi:181-188.

Quijada, Aníbal (1990). Cerco de púas, Santiago de Chile: Ediciones Fuego y Tierra (Primera Edición, en Cuba, Casa de las Américas, 1977).

Quinteros, Haroldo (1979). Diario de un preso político chileno. Madrid: Ediciones de la Torre.

Santos Herceg, José. "Testimonio y verdad: un falso dilema. El caso de la prisión política en Chile". Cuadernos de Literatura 36 (2014): 184-210.

Santos Herceg, José. “Los Centros de Detención y/o Tortura hoy. Su desaparición como destino". Revista Izquierdas 26 (2015): 256-275.

Silva, Macarena y Rojas, Fernanda (2004). Sufrimiento y desapariciones. El manejo urbanoarquitectónico de la memoria urbana traumatizada, Seminario de investigación, Departamento de Urbanismo, Facultad de Arquitectura y Urbanismo, Universidad de Chile. (También publicado en Editorial Arzobispado de Santiago-Fundación Documentación y Archivo de la Vicaría de la Solidaridad, 2005)

Silva, Macarena y Rojas, Fernanda (2011). "El manejo urbano-arquitectónico de la memoria urbana traumatizada”. Cüudad y Memorias. Desarrollo de Sitios de Conciencia en el Chile actual.Corporación Parque por la paz Villa Grimaldi: 78-84.

Tuan, Y. F., (2007). Topofilia. Un estudio de las percepciones, actitudes y valores sobre el entorno, Flor Durán de Zapata (trad.), Melusina (Topophilia: A Study of Environmental Perception. Attitudes and Values. Ed. Prentice-Hall. Nueva York, 1974).

Valdés, Hernán, (1978), Tejas verdes: Diario de un Campo de Concentración en Chile. Barcelona: Ediciones LAIA. (Primera edición en Editorial Ariel: Barcelona, 1974). 
Valenzuela, Hugo (2015). "Un parto en el desierto". Facebook.

Witker, Alejandro (1975). Chile; Prisión en Chile. México: FCE.

Yory, Carlos Mario (1998). Topofilia o la dimensión poética del habitar. Bogotá: CEJACOLCIENCIAS. 